\title{
Paying Obeisance to the Humble "Coconut": A Short Commentary
}

Every year, on $2^{\text {nd }}$ September, the world unites to thank the humble "coconut" for its immense benefits by observing the "World Coconut Day". The ever-popular coconut, apart from its other uses, has proven to have various health benefits.

Scientifically known as Cocos nucifera L., the coconut is a tree cultivated for its nutritional and medicinal values. Other products of coconut include tender coconut water, copra, coconut oil, raw kernel, coconut cake, coconut toddy, coconut shell and wood based products, coconut leaves, coir pith etc and these products are found in day to day use. ${ }^{1}$ Due to its many uses, it is often referred to as the "tree of life". ${ }^{2}$

The coconut fruit generally consists of $51.7 \%$ kernel, $9.8 \%$ water, and $38.5 \%$ shell and is an integral part of many South Asian diets. ${ }^{3}$ Beyond its usage in cooking, coconut oil has attracted attention due to its hypocholesterolemic, anticancer, antihepatosteatotic, antidiabetic, antioxidant, anti-inflammatory, antimicrobial and skin moisturizing properties.

An important component of the coconut, coconut water, in its natural form is a refreshing and nutritious beverage consumed widely due to its beneficial properties to health, mostly which are based on various cultural and/or traditional beliefs. ${ }^{4}$ Since ages, coconut water has been used for oral rehydration and even so for intravenous hydration of patients in remote/rural areas. ${ }^{5}$ Coconut water may also offer protection against myocardial infarction. ${ }^{5}$ As per the results of Alleyne T et al. (2005), regular consumption of either coconut water or mauby (a liquid extracted from the bark of the mauby tree, Colubrina arborescens), or particularly, a mixture of them, is effective in bringing about the control of hypertension. ${ }^{6}$
It also has been reported that Tender Coconut Water (TCW) and mature coconut water can reduce the occurrence of lifestyle diseases by reducing the risk of heart disease and has significant hypocholesterolemic, antioxidant and antithrombotic effects. Other researchers also have documented that immature coconut inflorescence helps lower blood glucose in diabetic rats. ${ }^{7}$

Medicinal Values: The various medicinal effects of coconut are as follows: ${ }^{1}$

- Electrolytic effect

- Antidote effect

- Antioxidant effect

- Cardioprotective effect

- Antithrombotic effect

- Antiatherosclerotic effect

- Hypolipidemic effect

- Anticholecystitic effect

- Antibacterial effect

- Anticaries effect

- Antidermatophytic effect

- Antiviral effect

- Antifungal effect

- Antiprotozoal effect

- Anticancer effect

- Immunostimulatory effect

- Antidiabetic effect

- Hepatoprotective effect

- Disinfectant effect

- Insect repellent

- Eco-friendly biodiesel

- Hormone like effect

The coconut palm has a significant effect on the rural 
economy of many coastal states where it is grown extensively and provides income to more than 10 million people. Therefore, it is of little amusement that the coconut culture is spreading even to nontraditional belts that, until recently, were considered unsuitable for the purpose.

\section{CONCLUSION}

This short commentary is a tribute to the humble coconut and educate people regarding the immense benefits of this humble "fruit". It is therefore only justified that a day is dedicated on the global level to celebrate the benefits provided by coconut and its products. Through further clinical and evidence-based studies, it is only a matter of time that coconut finds its way into the regular medical practice and drugs are prepared using its extract.

\section{REFERENCES}

1. DebMandal M, Mandal S. Coconut (Cocos nucifera L.: Arecaceae): in health promotion and disease prevention. Asian Pac J Trop Med. 2011;4(3):241-7. https://doi.org/10.1016/S1995-7645(11)60o78-3.

2. Chan E, Elevitch CR. Species profiles for Pacific island agroforestry, 2006. [Online Article]. Available from: www.traditionaltree.org [Accessed on $3^{\text {rd }}$ September, 2021]

3. Deen A, Visvanathan R, Wickramarachchi D, Marikkar N, Nammi S, Jayawardana BC, Liyanage R. Chemical composition and health benefits of coconut oil: an overview. J Sci Food Agric. 2021;101(6):2182-93. https://doi.org/10.1002/jsfa.10870.

4. Kobayashi H, Morisaki N, Tago Y, Hashimoto Y, Iwasaki S, Kawachi E, Nagata R, Shudo K. Structural identification of a major cytokinin in coconut milk as 14-O-(3-O-[ $\beta$-Dgalactopyranosyl-(1-->2)- $\alpha$-D-

galactopyranosyl-(1-->3)- $\alpha$-L-arabinofuranosyl]-4-O( $\alpha$-L-arabinofuranosyl)- $\beta$ - $\mathrm{D}$-galactopyranosyl)-transzeatin riboside. Chem Pharm Bull. 1997; 45:260-4.

5. Campbell-Falck D, Thomas T, Falck TM, Tutuo N, Clem K. The intravenous use of coconut water. Am J Emerg Med. 2000; 18:108-111.

6. Alleyne T, Roache S, Thomas C, Shirley A. The control of hypertension by use of coconut water and mauby: Two tropical food drinks. West Indian Med J. 2005;54:3-8.

7. Rajamohan T, Archana U. Nutrition and Health Aspects of Coconut. In: Nampoothiri K., Krishnakumar V., Thampan P., Nair M. (eds) The Coconut Palm (Cocos nucifera L.) - Research and Development Perspectives. $2018 \quad$ Springer, Singapore. https://doi.org/10.1007/978-981-13-2754-4_15

Cite this article as:

Jain S. Paying Obeisance to the Humble "Coconut": A Short Commentary. Int Healthc Res J. 2021;5(7)SC1-SC2. https://doi.org/10.26440/IHRJ/0507.10463

\section{$\frac{\text { AUTHOR AFFILIATION: }}{1 . \text { Reader, Depart }}$}

1. Reader, Department of Prosthodontics, Crown and Bridge, School of Dental Sciences (SDS), Sharda University, Greater Noida, 201306 (https://orcid.org/oooo-0oo2-3510-6791) 